\title{
ANALISIS PERTUMBUHAN DAN PRODUKSI TANAMAN BAWANG MERAH DENGAN PEMBERIAN PUPUK MONO KALIM PHOSPHATE PADA TANAH SUB OBTIMAL
}

\author{
Akhmad Sopian ${ }^{1}$ \\ ${ }^{1}$ Program Studi Agrotekhnologi Universitas Widya Gama Mahakam \\ Kampus Jl.K.H.Wahid Hasyim Sempaja Samarinda, Indonesia \\ Email: sopian@uwgm.ac.id
}

\begin{abstract}
ABSTRAK
Analisis Pertumbuhan dan Produksi Tanaman Bawang Merah dengan Pemberian Pupuk Mono Kalium Phosphate pada Tanah Sub Obtimal.

Potensi tanah di Kalimantan Timur cukup baik untuk pengembangan tanaman bawang merah. Target pengembangan bawang merah, di Kabupaten Paser seluas 20 hektare, Kabupaten Berau 30 hektare, Penajam Paser Utara dan Kutai Kartanegara masing-masing seluas 20 hektare. Penyiapan lahan yang baik dan pemberian hara yang cukup pada lahan sub obtimal akan menciptakan media tanaman yang baik dalam mendukung pertumbuhan dan produksi tanaman. Penelitian bertujuan untuk: merakit teknologi pengelolaan lahan suboptimal melalui penerapan pengelolaan lahan dan hara secara terpadu mengetahui potensi produksi bawang merah. Penelitian ini menggunakan Rancangan Acak Kelompok dengan jumlah 6 ulangan. Perlakuan pupuk cair mono kalium phosphate (MPK) terdiri atas 4 taraf konsentrasi yaitu : $\mathrm{P}_{0}=$ Kontrol $(10 \mathrm{~g}$ NPK Mutiara), $\mathrm{P}_{2}=2 \mathrm{~g} \mathrm{MPK} / /$ liter air, $\mathrm{P}_{3}=3 \mathrm{~g} \mathrm{MPK} /$ liter air, $\mathrm{P}_{4}=4 \mathrm{~g} \mathrm{MPK} /$ liter air. Hasil penelitian menunjukkan perlakuan pemberian pupuk cair mpk berpengaruh terhadap tinggi tanaman, jumlah umbi dan berat umbi. Bawang merah varietas Bima Brebes potensial untuk dikembangakan pada tanah ultisol dengan perbaikan sifat fisik dan kimia tanah. Pemupukan NPK mutiara yang ditabur pada tanah menunjukkan hasil yang efektif dibandingkan menggunakan pupuk cair MPK yang diberikan dengan cara disiram. Hasil ratarata jumlah umbi yang diberikan pupuk NPK mutiara yakni 11 umbi dengan berat rata-rata umbi 6,5 g.
\end{abstract}

Kata kunci : Bima Brebes, Potensi, Tanah Ultisol.

\begin{abstract}
Analysis Of Plant Growth and Production Of Shallot Plants by Giving Mono Potassium Phosphate Fertilizer on Sub Obtimal Soil.

The soil potential in East Kalimantan is quite good for the development of shallot plants. The target of shallot development is in Paser Regency covering an area of 20 hectares, Berau Regency 30 hectares, Penajam Paser Utara and Kutai Kartanegara each covering an area of 20 hectares. Good land preparation and sufficient nutrient provision in sub obtimal land will create a good plant medium to support plant growth and production. The research aims to: assemble suboptimal land management technologies through the application of integrated land and nutrient management to determine the potential for shallot production. This research used a randomized block design with 6 replications. The treatment of mono potassium phosphate (MPK) liquid fertilizer consists of 4 levels of concentration, namely: PO = Control $(10 \mathrm{~g} \mathrm{NPK}$ Mutiara), $P 2=2 \mathrm{~g} M P K / /$ liter water, $P 3=3 \mathrm{~g} M P K /$ liter water, $P 4=4 \mathrm{~g} M P K /$ liter of water.

The results showed that the treatment of mpk liquid fertilizer affected plant height, number of tubers and tuber weight. Bima Brebes variety of shallot has the potential to be cultivated on ultisolic soil by improving the physical and chemical properties of the soil. NPK pearl fertilization sown on the soil shows effective results compared to using MPK liquid fertilizer which is given by watering. The average yield of tubers given NPK pearl fertilizer was 11 tubers with an average tuber weight of $6.5 \mathrm{~g}$.
\end{abstract}

Key words : Bima Brebes, Potential, Ultisol Soil. 


\section{PENDAHULUAN}

Bawang merah merupakan salah satu jenis tanaman umbi yang memiliki nilai ekonomi yang tinggi. Prospek agribisnis bawang merah di Indonesia juga cukup baik, hal ini ditunjukkan oleh tingginya permintaan akan komoditas ini. Menurut Kementan (2019), konsumsi bawang merah rata-rata mencapai 2,76 $\mathrm{kg} / \mathrm{kapita} / \mathrm{tahun}$. Pada periode lima tahun terakhir produksi bawang merah mengalami peningkatan hingga $5,74 \%$ per tahun. Peningkatan produksi tersebut disebabkan oleh meningkatnya luas panen sebesar 3,70\% dan produksi naik 2,00\% per tahun (Ardi, 2018).

Tanaman bawang merah (Allium ascalonicum L.) merupakan tanaman hortikultura yang semakin mendapat perhatian baik dari masyarakat maupun pemerintah. Selama beberapa tahun terakhir ini, bawang merah termasuk enam besar komoditas sayuran yang diekspor bersama-sama dengan kubis, blunkol (kubis bunga), cabai, tomat, dan kentang. Bahkan bawang merah ini tidak hanya diekspor dalam bentuk sayuran segar, tetapi juga setelah diolah menjadi produk bawang goreng (Rukmana, 1995).

Kementerian Pertanian dalam tahun anggaran 2017 melakukan pengembangan komoditas bawang merah seluas 100 hektare di Provinsi Kalimantan Timur, demi untuk mencukupi kebutuhan lokal yang selama ini hanya terpenuhi 30 persen. Berdasarkan angka tetap tahun 2016, produksi bawang merah yang dihasilkan petani lokal sebanyak 263 ton. Jumlah ini hanya tercukupi sekitar 30 persen dari kebutuhan lokal (Distan, 2017). Pengembangan 100 ha bawang merah itu tersebar di lima kabupaten/kota di Provinsi Kaltim, yakni Kabupaten Paser seluas 20 ha, Penajam Paser Utara 20 ha, Berau 30 ha, Kutai Kartanegara 20 ha, dan Balikpapan 10 ha. Hasil penelitian Burhanudin dan Syukur (2006) dengan perlakuan pupuk kandang menunjukkan pengaruh nyata terhadap pertumbuhan dan produksi bawang merah.

Dalam proses budidaya, peningkatan produksi tanaman dapat dilakukan secara agronomik yaitu melalui pemupukan.

Pemupukan perlu dilakukan untuk mengganti kehilangan unsur hara dalam tanah akibat pencucian serta bertujuan untuk memenuhi kebutuhan unsur hara bagi tanaman sehingga dapat meningkatkan produktivitas tanaman (Susila dkk., 2010)

Pemupukan dapat dilakukan dengan menggunakan pupuk anorganik maupun pupuk organik. Pupuk anorganik lebih banyak digunakan dengan alasan lebih cepat dalam penyediaan unsur hara dibandingkan dengan pupuk organik. Urea, SP-36, dan KCL termasuk pupuk anorganik yang mengandung unsur nitrogen, pospor,dan kalium. Ketiga unsur merupakan unsur hara makro yang mempunyai peranan sangat penting dalam pertumbuhan tanaman dan produksi tanaman. Menurut Hardjowigeno (2007) unsur hara esensial adalah unsur hara yang sangat diperlukan oleh tanaman diantaranya adalah N,P, dan $\mathrm{K}$.

Interaksi pupuk $\mathrm{N}$ dan $\mathrm{K}$ tidak nyata terhadap jumlah tanaman yang tumbuh per plot, jumlah anakan per rumpun, diameter umbi, jumlah umbi per rumpun, dan jumlah umbi per plot (Napitupulu and Winarto 2010). Hasil penelitian terhadap perlakuan pupuk kandang yang di aplikasikan pada tanah Alfisol menunjukkan produksi bawang merah signifikan dibandingkan pada tanah vertisol. (Purnawanto and Budi, 2008).

Penelitian bertujuan untuk: merakit teknologi pengelolaan lahan suboptimal melalui penerapan pengelolaan lahan dan hara secara terpadu mengetahui potensi produksi bawang merah. 


\section{METODA PENELITIAN}

\subsection{Tempat dan Waktu}

Penelitian ini dilaksanakan pada lahan pertanian Kelurahan air putih Kecamatan Samarinda Ulu, pelaksanaan penelitian selama 5 bulan mulai April sampai dengan Agustus 2020.

\subsection{Bahan dan Alat}

Alat-alat yang digunakan dalam penelitian ini antara lain: parang, cangkul, meteran, tali rafia, lingga, timbangan, ember, sprayer, alat-alat tulis dan kamera untuk dokumentasi. Sedangkan bahan yang digunakan adalah: benih bawang merah varites bima Brebes, insektisida matador, pupuk urea, pupuk cair Mono Kalium Phosphate (MPK), dan pupuk NPK Mutiara.

\subsection{Rancangan Penelitian}

Penelitian ini menggunkan Rancangan Acak Kelompok (RAK) dengan 6 ulangan. Perlakuan pupuk mono kalium phosphate (MPK) terdiri atas 4 taraf konsentrasi yaitu : $\mathrm{P}_{0}=$ kontrol (5 g NPK mutiara), $\mathrm{P}_{2}=$ $2 \mathrm{~g}$ MPK/liter air, $\mathrm{P}_{3}=3 \mathrm{~g}$ MPK/liter air, $\mathrm{P}_{4}=4 \mathrm{~g} \mathrm{MPK} /$ liter air. Jumlah petak yang digunakan dalam penelitian ni 24 dengan ukuran masing masing petak $60 \times 100 \mathrm{~cm}$

\subsection{Pelaksanaan Penelitian}

Lahan dipersiapkan dengan membuat petak ukuran $150 \mathrm{~cm} \quad x \quad 75 \mathrm{~cm}$ sebanyak 6 petak sebagai ulangan. Dalam setiap petak terdiri atas 4 perlakuan dimana setiap perlakuan ada tiga tanaman. Lahan diolah dengan cangkul sebanyak 2 kali pengolahan sehingga tanah dalam keadaan gembur, tinggi bedeng $20 \mathrm{~cm}$ (Gambar 1). Lahan dibiarkan selama satu minggu baru ditanam benih berupa umbi bawang merah.

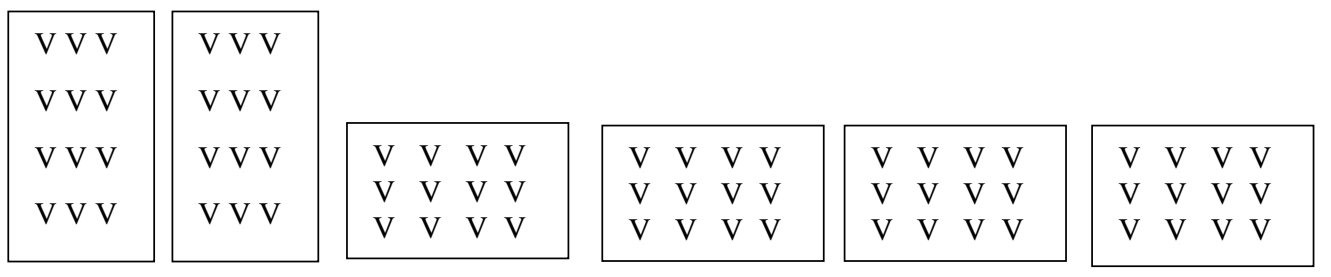

Gambar 1. Sket Lahan Penelitian jarak tanam 15 x $30 \mathrm{~cm}$

Penyiraman dilakukan dua kali pagi dan sore, jika hujan tidak dilakukan penyiraman. Pada umur satu bulan dilakukan pengendalian hama busuk daun dengan menyemprotkan insektisida matador dengan dosis 1 $\mathrm{ml} /$ liter air dengan penyemprotan setiap satu minggu sekali.

Perlakuan diberikan setelah tanaman berumur satu bulan dengan tinggi 10 $\mathrm{cm}$ maka diberikan pupuk urea sebagai pupuk dasar dengan dosis 5 gram pertanaman. Pupuk Mono
Kalium Phosphate (MPK) sebagai perlakuan diberikan setelah tanaman berumur 1,5 bulan $\left(\mathrm{P}_{2}, \mathrm{P}_{3}, \mathrm{P}_{4}\right)$ dengan cara melarutkan dalam air dengan konsentrasi sesuai perlakuan yang diberikan dengan disiram ke tanah. Perlakuan kontrol (tanpa pupuk MPK) namun diberikan pupuk NPK mutiara dengan dosis 10 gram yang ditaburkan disekitar tanaman.

Panen dilakukan stelah tanaman berumur 4 bulan dengan kriteria umbi bawang telah muncul ketanah dan 
menimbulkan bau, subagian daun telah menguning, dan bagian batang daun telah patah, umbi telah mengeras.

\subsection{Analisis Data}

Parameter yang diamati yakni tinggi tanaman, jumlah umbi, berat umbi per rumpun, dan berat umbi yang terbesar pada setiap rumpun yang diambil pada akhir penelitian yakni tanaman berumur empat bulan. Untuk melihat respon pertumbuhan tanaman terhadap perlakukan pemberian dua jenis bahan organik dilakukan analisis ragam, apabila hasil analisis ragam berbeda nyata, maka dilanjutkan dengan Uji Beda Nyata Terkecil (BNT) pada taraf 5 persen (Gomez K and Gomez A, 1995).

\section{HASIL PENELITIAN DAN PEMBAHASAN}

\section{Tinggi Tanaman}

Hasil sidik ragam menunjukkan bahwa perlakuan pemberian pupuk fosphor dan kalium berpengaruh nyata terhadap pertumbuhan tinggi tanaman bawang merah. Rata-rata tinggi tanaman bawang umur 4 bulan disajikan pada tabel 2 :

Tabel 2. Rata-Rata Tinggi Tanaman Bawang Merah yang diberikan Perlakuan Pupuk Fosphor dan Kalium umur 4 bulan $(\mathrm{cm})$

\begin{tabular}{cccccccc}
\hline \multirow{2}{*}{ Perlakuan } & \multicolumn{9}{c}{ Ulangan } & \multicolumn{2}{c}{ Rata Rata } \\
\cline { 2 - 8 } & 1 & 2 & 3 & 4 & 5 & 6 & \\
\hline $\mathrm{P}_{0}$ & 30 & 32 & 32 & 32 & 29 & 29 & $30.67^{\mathrm{a}}$ \\
$\mathrm{P}_{2}$ & 23 & 22 & 25 & 26 & 32 & 27 & $25.83^{\mathrm{b}}$ \\
$\mathrm{P}_{3}$ & 25 & 24 & 25 & 26 & 25 & 29 & $25.67^{\mathrm{b}}$ \\
$\mathrm{P}_{4}$ & 33 & 23 & 23 & 24 & 23 & 30 & $26.00^{\mathrm{b}}$ \\
\hline
\end{tabular}

*) Angka rata - rata yang diikuti huruf yang sama menunjukkan tidak berbeda nyata pada uji BNT 5\% (BNT P =2,26 )

Hasil uji BNT 5\% menunjukkan perlakuan $\mathrm{P}_{2}, \mathrm{P}_{3}$, dan $\mathrm{P}_{4}$ berbeda terhadap kontrol $\left(\mathrm{P}_{0}\right)$ antara $\mathrm{P}_{2}, \mathrm{P}_{3}$, dan $\mathrm{P}_{4}$ tidak berbeda nyata. Hasil terbaik pada perlakuan $\mathrm{P}_{0}$ dengan tinggi tanaman $30,67 \mathrm{~cm}$. Tinggi tanaman pada perlakuan kontrol $\left(\mathrm{P}_{0}\right)$ lebih tinggi dibandingkan dengan perlakuan yang diberikan pupuk MPK cair. $\mathrm{P}_{0}$ diberikan pupuk NPK menunjukkan pertumbuhan yang lebih baik dibandingkan perlakuan pupuk cair. Hal ini diduga pupuk N P K yang diberikan lewat tanah lebih efektif dibandingkan dengan pupuk cair. Pemberian pupuk dengan cara ditabur lebih efektif dibandingkan dengan cara
siram.(Kusuma, Rosniawaty, and Maxiselly 2019)

Tinggi tanaman bawang merah yang diberikan biourine pada umur 56 hari dapat mencapai tinggi $32,92 \mathrm{~cm}$. (Tandi, Paulus, and Pinaria 2015).

\section{Jumlah Umbi}

Hasil sidik ragam menunjukkan bahwa perlakuan pemberian pupuk fosphor dan kalium berpengaruh nyata terhadap jumlah umbi tanaman bawang merah. Rata-rata jumlah umbi tanaman bawang merah disajikan pada Tabel 3 : 
Tabel 3. Rata-rata Jumlah Umbi Bawang Merah yang diberikan Perlakuan Pupuk Fosphor dan Kalium

\begin{tabular}{ccccccccc}
\hline \multirow{2}{*}{ Perlakuan } & \multicolumn{3}{c}{ Ulangan } & \multicolumn{2}{c}{ Rata } \\
\cline { 2 - 7 } & 1 & 2 & 3 & 4 & 5 & 6 & Rata \\
\hline $\mathrm{P}_{0}$ & 8 & 7 & 7 & 5 & 7 & 9 & $7.17^{\mathrm{a}}$ \\
$\mathrm{P}_{2}$ & 9 & 9 & 7 & 9 & 8 & 8 & $8.33^{\mathrm{ab}}$ \\
$\mathrm{P}_{3}$ & 10 & 8 & 11 & 9 & 9 & 10 & $9.50^{\mathrm{b}}$ \\
$\mathrm{P}_{4}$ & 7 & 6 & 6 & 8 & 7 & 10 & $7,33^{\mathrm{a}}$ \\
\hline
\end{tabular}

*) Angka rata - rata yang diikuti huruf yang sama menunjukkan tidak berbeda nyata pada uji BNT 5\% $(\mathrm{BNT} \mathrm{P}=1,35)$

Hasil uji BNT 5\% menunjukkan perlakuan $\mathrm{P}_{3}$ berbeda terhadap kontrol $\left(\mathrm{P}_{0}\right)$ dengan rata rata jumlah umbi terbanyak yaitu 9,5 butir. Perlakuan $\mathrm{P}_{2}$, dan $\mathrm{P}_{4}$ tidak berbeda nyata terhadap kontrol. Jumlah umbi pada P0 7,17 relatif sama dengan jumlah pada perlakuan $\mathrm{P}_{2}$ dan $\mathrm{P}_{4}$. Potensi produksi bawang pada tanah ini cukup baik yakni berkisar $5-11$ umbi (Gambar 2). Menurut Ardi (2018) Varietas Bima Brebes cocok ditanam pada dataran rendah dengan produksi dalam 1 rumpun menghasilkan 7-12 buah anakan. Hasil penelitian WA, R, and Sitepu FE (2014) dalam penelitian pada jenis tanah ultisol diperoleh jumlah anakan rata rata 6,03 buah. Hasil penelitian terhadap bobot umbi yang diberikan pupuk NPK mencapai 7-9 umbi.(Mehran, Kesumawaty, and Sufardi 2016). Berdasarkan jumlah umbi menunjukkan bahwa potensi bawang merah yang ditanam pada tanah ultisol di Kalimantan Timur cukup baik hasilnya. Hasil penelitian terhadap jumlah umbi hasil penelitian yang dilakukan pada tanah alfisol rata rata 6,4 buah sedangkan pada tanah vertisol 5,7 buah (Purnawanto and Budi 2008).

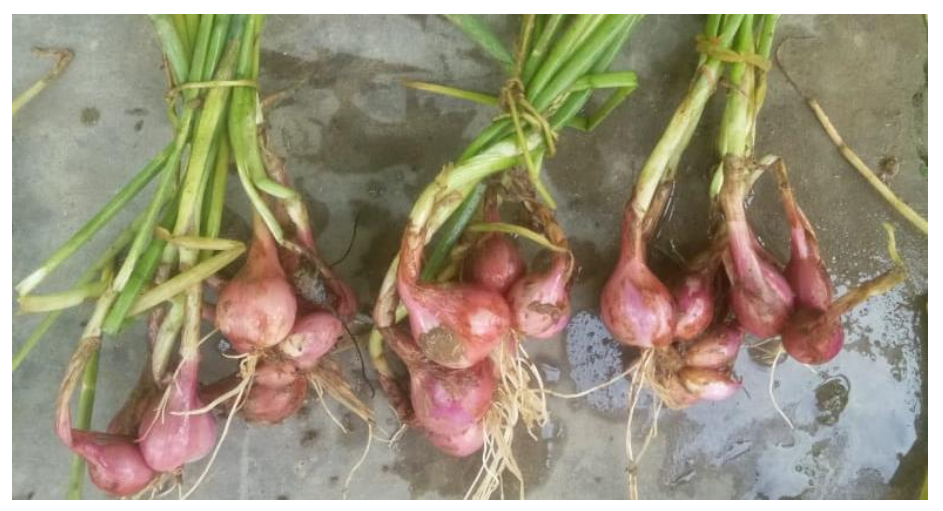

Gambar 2. Jumlah umbi 5 sd 11 butir

\section{Berat Umbi}

Hasil sidik ragam menunjukkan bahwa perlakuan pemberian pupuk fosphor dan kalium berpengaruh nyata terhadap berat umbi tanaman bawang merah. Rara-rata berat umbi tanaman bawang disajikan pada Tabel 4 : 
Tabel 4. Rata-rata Berat Umbi Bawang Merah yang diberikan Perlakuan Pupuk Fosphor dan Kalium

\begin{tabular}{cccccccc}
\hline \multirow{2}{*}{ Perlakuan } & \multicolumn{9}{c}{ Ulangan } & \multicolumn{2}{c}{ Rata Rata *) } \\
\cline { 2 - 7 } & 1 & 2 & 3 & 4 & 5 & 6 & \\
\hline $\mathrm{P}_{0}$ & 6.00 & 7.00 & 6.00 & 7.00 & 6.00 & 7.00 & $6.50^{\mathrm{a}}$ \\
$\mathrm{P}_{2}$ & 3.00 & 3.00 & 3.00 & 3.00 & 4.00 & 2.00 & $3.00^{\mathrm{b}}$ \\
$\mathrm{P}_{3}$ & 4.00 & 3.00 & 4.00 & 3.00 & 3.00 & 3.00 & $3.33^{\mathrm{b}}$ \\
$\mathrm{P}_{4}$ & 4.00 & 3.00 & 4.00 & 3.00 & 3.00 & 4.00 & $3.50^{\mathrm{b}}$ \\
\hline
\end{tabular}

*) Angka rata - rata yang diikuti huruf yang sama menunjukkan tidak berbeda nyata pada uji BNT 5\% $(\mathrm{BNT} \mathrm{P}=0,79)$

Hasil uji BNT 5\% menunjukkan perlakuan $\mathrm{P}_{2}, \mathrm{P}_{3}$, dan $\mathrm{P}_{4}$ berbeda terhadap kontrol $\left(\mathrm{P}_{0}\right)$ antara $\mathrm{P}_{2}, \mathrm{P}_{3}$, dan $\mathrm{P}_{4}$ tidak berbeda nyata. Hasil terbaik pada perlakuan $\mathrm{P}_{2}$ dengan rata rata berat umbi 6,5 gram (Gambar 3). Rata rata berat umbi pada perlakuan kontrol $\left(\mathrm{P}_{0}\right)$ lebih tinggi dibadingkan dengan perlakuan pupuk MPK cair. Berat umbi pada perlakuan $\mathrm{P}_{2}, \mathrm{P}_{3}$, dan $\mathrm{P}_{4}$ relatif sama. Diduga berat umbi berkorelasi dengan pertumbuhan tanaman. Sesuai dengan hasil penelitian Palupi dan Alfandi (2018) bahwa ada korelasi yang signifikan antara jumlah daun per rumpun dengan berat umbi kering.

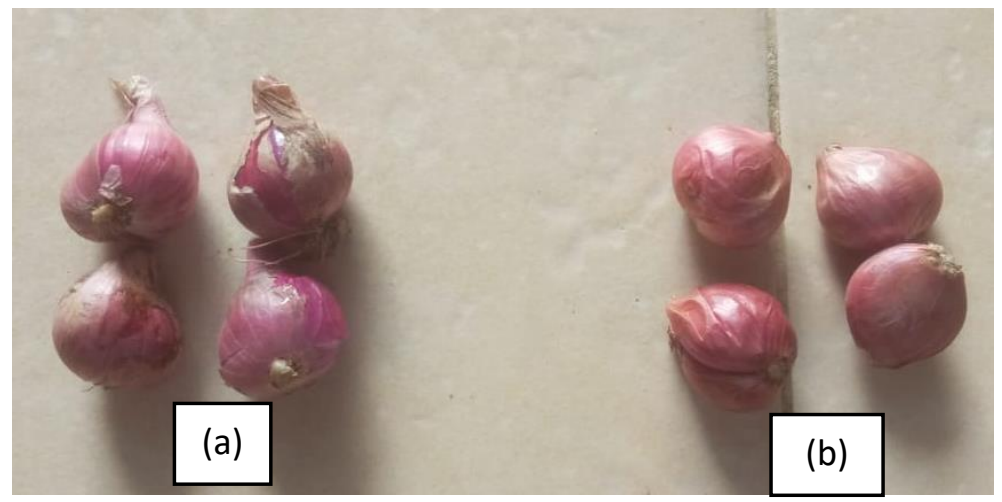

Gambar 3. Berat umbi (a) umbi dengan perlakuan NPK (kontrol) rata rata berat 6,5 gram (b) umbi sebagai benih ; rata rata berat 5 gram

Dilihat dari Gambar 3 Berat umbi hasil penelitian yang ditanam pada tanah ultisol lebih besar dari umbi yang dijadikan benih. Hasil ini menyimpulkan bahwa di wilayah penelitian potensi untuk dikembangkan tanaman bawang merah.
Hasil sidik ragam menunjukkan bahwa perlakuan pemberian pupuk fosphor dan kalium tidak berpengaruh nyata terhadap produksi umbi tanaman bawang merah per rumpun. Rata-rata produksi umbi per rumpun tanaman bawang per rumpun disajikan pada Tabel 5 :

\section{Produksi Umbi}


Tabel 5. Rata-rata Produksi Umbi Bawang Merah Per Rumpun yang diberikan Perlakuan Pupuk Fosphor dan Kalium (gram)

\begin{tabular}{cccccccc}
\hline \multirow{2}{*}{ Perlakuan } & \multicolumn{9}{c}{ Ulangan } & \multicolumn{3}{c}{ Rata Rata } \\
\cline { 2 - 8 } & 1 & 2 & 3 & 4 & 5 & 6 & \\
\hline $\mathrm{P}_{0}$ & 43 & 38 & 39 & 36 & 32 & 31 & 36.50 \\
$\mathrm{P}_{2}$ & 43 & 35 & 30 & 41 & 52 & 31 & 38.67 \\
$\mathrm{P}_{3}$ & 38 & 30 & 46 & 40 & 33 & 58 & 40.83 \\
$\mathrm{P}_{4}$ & 37 & 32 & 37 & 32 & 30 & 39 & 34.50 \\
\hline
\end{tabular}

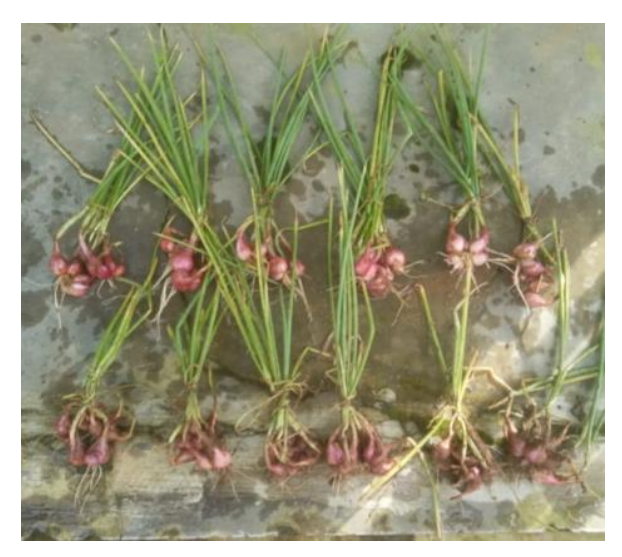

Gambar 4. Produksi Umbi Per Rumpun

Produksi umbi per rumpun (Gambar 4) tidak menunjukkan hasil yang signifikan dimana produksi umbi per rumpun pada kontrol (P0) yaitu 36,50 gram sedangkan produksi umbi P2 yaitu 38,67 gram, P3 yaitu 40,83 gram, dan P4 yaitu 34,50 gram. Penambahan pupuk tidak diikuti peningkatan produksi.

Pada perlakuan $\mathrm{P}_{2}, \mathrm{P}_{3}$, dan $\mathrm{P}_{4}$ tidak berpengaruh nyata karena umbi yang dihasilkan relatif kecil dibadingkan dengan umbi pada perlakuan kontrol $\left(\mathrm{P}_{0}\right)$ sehingga berpengaruh terhadap berat per rumpun. Berdasarkan berat umbi perbutir menunjukkan bahwa tanaman bawang merah mempunyai potensi untuk dikembangkan di Kalimantan Timur, namun demikian produksi per rumpun tersebut rendah diduga kesuburan di tempat penelitian sangat rendah. Sesuai dengan pernyataan Ardi (2018) varietas bima cocok dikembangkan pada datara rendah namun tidak mudah beradaptasi dengan lingkungan yang tidak produktif.

\section{KESIMPULAN}

Bawang merah varietas Bima Brebes potensial untuk dikembangakan pada tanah ultisol dengan perbaikan sifat fisik dan kimia tanah. Jumlah umbi mencapai 11 buah dengan berat rata rata 6,5 gram. Pemupukan menggunakan $\mathrm{N}, \mathrm{P}, \mathrm{K}$ mutiara yang diberikan lewat tanah lebih efektif dibandingkan menggunakan pupuk MPK cair yang diberikan dengan cara disiram.

\section{UCAPAN TERIMA KASIH}

Ucapan terimakasih disampaikan kepada YPPM Samarinda dan LPPM Universitas Widya Gama Mahakam Samarinda untuk pembiayaan penelitian ini melalui Diva Tahun Anggaran 2019/2020 serta membantu memberikan sarana, prasarana, dan kesempatan kepada penulis untuk melaksanakan penelitian. 


\section{DAFTAR PUSTAKA}

Ardi E. (2018). Bawang Merah, Teknik Budidaya dan Peluang Usaha. Yogyakarta: Trans Idea Publishing.

Burhanudin dan Syukur (2006) Pertumbuhan dan Hasil Bawang Merah (Allium ascalanicum L) Pada Berbagai Pupuk Kandang. Jurnal Agroland 13(3); 265-269.

Distan Kaltim. (2017). Kementan Kembangkan 100 Hektar Bawang Merah Kaltim, Antara Kaltim, Samarinda.

Gomez K and Gomez A, (1995). Prosedur Statistik Untuk Penelitian Pertanian. Terjemahan Syamsudin E dan Baharsjah JS.Jakarta: UI Press.

Hardjowigeno, S.(2007). Ilmu Tanah. Jakarta: Akademika Pressindo.

Kementan, (2019). Buletin Pangan (Konsumsi dan Neraca Penyediaan dan Penggunaan Bawang Merah) 10 (1) 1-96.

Kusuma, Arkan Azis, Santi Rosniawaty, and Yudithia Maxiselly. (2019). "Pengaruh Asam Humat Dan Pupuk Kandang Sapi Terhadap Pertumbuhan Tanaman Kakao (Theobroma Cacao L.) Belum Menghasilkan Klon Sulawesi 1." Kultivasi 18(1):46-52.

Mehran, M., E. Kesumawaty, and S. Sufardi. (2016). "Pertumbuhan Dan Hasil Beberapa Varietas Bawang Merah (Allium Ascalonicum L) Pada Tanah Aluvial Akibat Pemberian Berbagai Dosis ...." Jurnal Floratek 11:117-33.

Napitupulu, D. and L. Winarto. (2010). "Pengaruh Pemberian Pupuk N Dan K Terhadap Pertumbuhan Dan Produksi Bawang Merah." Jurnal
Hortikultura 20(1):136783.

Palupi T dan Alfandi. (2018). Pengaruh Jarak Tanam Dan Pemotongan Umbi Bibit Terhadap Pertumbuhan Dan Hasil Tanaman Bawang Merah (Allium Ascalonicum L.) Varietas Bima Brebes. Agroswagati Jurnal Agronomi, 6(1).

Purnawanto, agus mulyadi and gayuh prasetyo Budi. (2008). "Kajian Pengembangan Bawang Merah Pada Lahan Berkadar Liat Tinggi (Vertisol) Dengan Penambahan Pupuk Organik." Agritech x(2):108 20.

Susila, AD, JG Kartika, T Prasetyo, dan MC Palada. (2010). Fertilizer recommendation: correlation and calibration study of soil $\mathrm{P}$ test for yard long bean (Vigna unguilata L.) on Ultisols in Nanggung-Bogor. Jurnal Agron Indonesia. 38 (3): 225-231.

Tandi, Olvie G., J. Paulus, and A Pinaria. (2015). "Pertumbuhan Dan Produksi Bawang Merah (Allium Ascalonicum L.) Berbasis Aplikasi Biourine Sapi." Eugenia 21(3):14250.

WA, Tambunan, Sipayung R, and Sitepu FE. (2014). "Pertumbuhan Dan Produksi Bawang Merah (Allium Ascalonicum L.) Dengan Pemberian Pupuk Hayati Pada Berbagai Media Tanam.Jurnal Online Agroteknologi." IEEE International Conference on Acoustics, Speech, and Signal Processing (ICASSP) 2014 41(2):84-93.

Winarso. (2005). Kesuburan Tanah, Dasar Kesehatan dan Kualitas Tanah. Yogyakarta: Gava Media. 